This item was submitted to Loughborough's Research Repository by the author.

Items in Figshare are protected by copyright, with all rights reserved, unless otherwise indicated.

\title{
Perpendicular growth characteristics of Cu-Sn intermetallic compounds at the surface of Sn99Cu1/Cu solder interconnects
}

\section{PLEASE CITE THE PUBLISHED VERSION}

http://dx.doi.org/10.1007/s11664-015-4043-7

\section{PUBLISHER}

(c) The Minerals, Metals \& Materials Society. Published by Springer.

\section{VERSION}

AM (Accepted Manuscript)

\section{PUBLISHER STATEMENT}

This work is made available according to the conditions of the Creative Commons Attribution-NonCommercialNoDerivatives 4.0 International (CC BY-NC-ND 4.0) licence. Full details of this licence are available at: https://creativecommons.org/licenses/by-nc-nd/4.0/

\section{LICENCE}

CC BY-NC-ND 4.0

\section{REPOSITORY RECORD}

Chen, Zhiwen, Changqing Liu, Yiping Wu, and Bing An. 2019. "Perpendicular Growth Characteristics of Cu-sn Intermetallic Compounds at the Surface of Sn99cu1/cu Solder Interconnects". figshare. https://hdl.handle.net/2134/19455. 


\section{Metadata of the article that will be visualized in OnlineFirst}

\begin{tabular}{|c|c|c|}
\hline \multicolumn{3}{|c|}{ Please note: Images will appear in color online but will be printed in black and white. } \\
\hline Article CopyRight & \multicolumn{2}{|c|}{$\begin{array}{l}\text { The Minerals, Metals \& Materials Society } \\
\text { (This will be the copyright line in the final PDF) }\end{array}$} \\
\hline \multirow[t]{5}{*}{ Corresponding Author } & Family Name & Liu \\
\hline & Particle & \\
\hline & Given Name & Changqing \\
\hline & Suffix & \\
\hline & Email & C.Liu@lboro.ac.uk \\
\hline \multirow[t]{7}{*}{ Author } & Family Name & Chen \\
\hline & Particle & \\
\hline & Given Name & Zhiwen \\
\hline & Suffix & \\
\hline & Division & \\
\hline & Organization & Huazhong University of Science and Technology \\
\hline & Address & Wuhan, Hubei, People's Republic of China \\
\hline \multirow[t]{8}{*}{ Author } & Family Name & $\mathbf{W u}$ \\
\hline & Particle & \\
\hline & Given Name & Yiping \\
\hline & Suffix & \\
\hline & Division & \\
\hline & Organization & Huazhong University of Science and Technology \\
\hline & Address & Wuhan, Hubei, People's Republic of China \\
\hline & Email & \\
\hline \multirow[t]{6}{*}{ Author } & Family Name & An \\
\hline & Particle & \\
\hline & Given Name & Bing \\
\hline & Suffix & \\
\hline & Division & \\
\hline & Organization & Huazhong University of Science and Technology \\
\hline
\end{tabular}


Schedule

Revised

Accepted

4 September 2015

Abstract

The growth of intermetallic compounds (IMCs) on the free surface of 99Sn-1Cu solder joints perpendicular to the interdiffusion direction has been investigated in this work. The specimens were specifically designed and polished to reveal a flat free surface at the solder/Cu interface for investigation. After aging at $175^{\circ} \mathrm{C}$ for progressively increased durations, the height of the perpendicular IMCs was examined and found to follow a parabolic law with aging duration that could be expressed as $y=0.11 \sqrt{t}$, where $t$ is the aging duration in hours and $y$ is the height of the perpendicular IMCs in $\mu \mathrm{m}$. For comparison, the planar growth of IMCs along the interdiffusion direction was also investigated in $99 \mathrm{Sn}-1 \mathrm{Cu} / \mathrm{Cu}$ solder joints. After prolonged aging at $175^{\circ} \mathrm{C}$, the thickness of the planar interfacial IMC layers also increased parabolically with aging duration and could be expressed as $h_{\mathrm{IMC}}=0.27 \sqrt{t}+4.6$, where $h$ is the thickness in $\mu \mathrm{m}$ and $t$ is the time in hours. It was found that both the planar and perpendicular growth of the IMCs were diffusion-controlled processes, but the perpendicular growth of the IMCs was much slower than their planar growth due to the longer diffusion distance. It is proposed that $\mathrm{Cu}_{3} \mathrm{Sn}$ forms prior to the formation of $\mathrm{Cu}_{6} \mathrm{Sn}_{5}$ in the perpendicular IMCs, being the reverse order compared with the planar IMC growth.

Keywords (separated by '-') Solder joint - planar growth of IMCs - perpendicular growth of IMCs - interdiffusion - growth rate formation sequence of IMCs

Footnote Information 


\title{
3 Perpendicular Growth Characteristics of Cu-Sn Intermetallic 4 Compounds at the Surface of $99 \mathrm{Sn}-1 \mathrm{Cu} / \mathrm{Cu}$ Solder 5 Interconnects
}

\author{
ZHIWEN CHEN, ${ }^{1,2}$ CHANGQING LIU, ${ }^{2,3}$ YIPING WU, ${ }^{1}$ and BING $\mathrm{AN}^{1}$ \\ 1.-Huazhong University of Science and Technology, Wuhan, Hubei, People's Republic of China. \\ 2.-Loughborough University, Loughborough, Leicestershire LE11 3TU, UK. 3.-e-mail: \\ C.Liu@lboro.ac.uk
}

The growth of intermetallic compounds (IMCs) on the free surface of $99 \mathrm{Sn}-1 \mathrm{Cu}$ solder joints perpendicular to the interdiffusion direction has been investigated in this work. The specimens were specifically designed and polished to reveal a flat free surface at the solder/Cu interface for investigation. After aging at $175^{\circ} \mathrm{C}$ for progressively increased durations, the height of the perpendicular IMCs was examined and found to follow a parabolic law with aging duration that could be expressed as $y=0.11 \sqrt{t}$, where $t$ is the aging duration in hours and $y$ is the height of the perpendicular IMCs in $\mu \mathrm{m}$. For comparison, the planar growth of IMCs along the interdiffusion direction was also investigated in $99 \mathrm{Sn}-1 \mathrm{Cu} / \mathrm{Cu}$ solder joints. After prolonged aging at $175^{\circ} \mathrm{C}$, the thickness of the planar interfacial IMC layers also increased parabolically with aging duration and could be expressed as $h_{\mathrm{IMC}}=0.27 \sqrt{t}+4.6$, where $h$ is the thickness in $\mu \mathrm{m}$ and $t$ is the time in hours. It was found that both the planar and perpendicular growth of the IMCs were diffusion-controlled processes, but the perpendicular growth of the IMCs was much slower than their planar growth due to the longer diffusion distance. It is proposed that $\mathrm{Cu}_{3} \mathrm{Sn}$ forms prior to the formation of $\mathrm{Cu}_{6} \mathrm{Sn}_{5}$ in the perpendicular IMCs, being the reverse order compared with the planar IMC growth.

Key words: Solder joint, planar growth of IMCs, perpendicular growth of IMCs, interdiffusion, growth rate, formation sequence of IMCs

\section{INTRODUCTION}

In electronic devices, the interconnections between components are normally formed by reflowing solder alloys. During such reflow, the reactions between the solder and substrate are essential to the formation of reliable solder interconnects. However, the interfacial intermetallic compound (IMC) layers produced during reflow can grow continuously during subsequent service due to interdiffusion and solid-state reactions, particularly when devices are exposed to elevated temperature. Excessive growth of interfacial IMC layers can significantly deteriorate the mechanical integrity of

(Received February 23, 2015; accepted September 4, 2015) the entire solder joint because of the incompatible mechanical properties of the interfacial IMC layers in comparison with the solder alloy and substrate. ${ }^{1-3}$ Hence, growth of IMCs at the solder/substrate interface has received continuous attention from researchers. ${ }^{4-8}$

The interfacial IMC layers extensively investigated in literature normally cover the entire solder/substrate interface and grow along the direction of interdiffusion between the solder and substrate. $^{4-8}$ Therefore, this type of interfacial IMC layer is termed the planar IMC layer in this work, as illustrated in Fig. 1. Moreover, IMCs (i.e., Cu-Sn IMCs) can also protrude out of the free surface of solder joints, perpendicular to the diffusion direction within the solder joint, ${ }^{9}$ as illustrated in Fig. 1. This is termed the perpendicular IMC in this work.

\begin{tabular}{|l|lll|}
\hline Journal : 11664_JEM & Dispatch : 18-9-2015 & Pages : 10 \\
& & $\square$ LE & $\square$ TYPESET \\
\hline
\end{tabular}




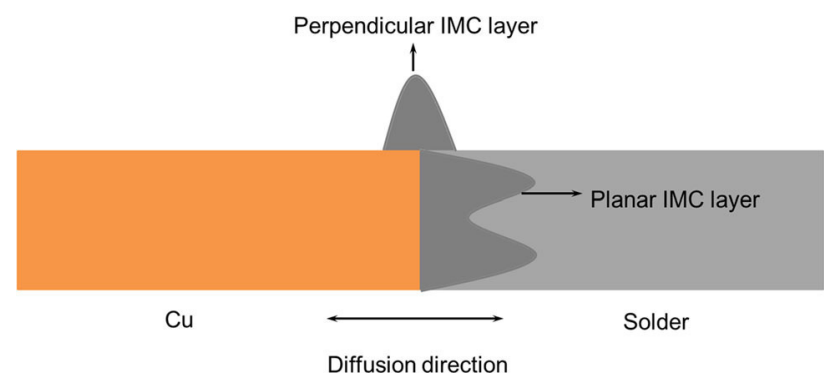

Fig. 1. Planar and perpendicular growth of IMCs at the $99 \mathrm{Sn}-1 \mathrm{Cu} /$ $\mathrm{Cu}$ interface in solder joints.

In contrast to the numerous works reported on characterization of planar IMCs in solder joints, the perpendicular growth of IMCs has seldom been investigated. The mechanism of the perpendicular growth of IMCs also remains unclear. In electromigration tests, it was suggested that such perpendicular IMCs were "squeezed out" by compressive stress induced by current stressing at the interface in the solder joint. ${ }^{9,10}$ However, study on the spreading of IMCs implied that interdiffusion of atoms on the free surface can also result in growth of IMCs on the free surface. ${ }^{11}$

In this study, the perpendicular growth of IMCs was investigated in specifically designed $99 \mathrm{Sn}-1 \mathrm{Cu} /$ $\mathrm{Cu}$ solder joints. The top surface of the solder joints was polished and profiled using a white-light interferometer after gradually prolonged aging at $175^{\circ} \mathrm{C}$ to measure the height of the perpendicular IMCs. Scanning electron microscopy (SEM) was employed to examine the morphology of the perpendicular IMCs from the top, and cross-sectional views were prepared by focused ion beam (FIB). In comparison, the ordinary planar growth of interfacial IMC layers at the $99 \mathrm{Sn}-1 \mathrm{Cu} / \mathrm{Cu}$ interface was also characterized by grinding and polishing to reveal the cross-section of the solder joints after aging at the same temperature for increasing periods. Correlations and differences between the IMC growth along these two directions are also presented.

\section{EXPERIMENTAL PROCEDURES}

\section{Perpendicular Growth of IMCs}

To investigate the perpendicular growth of IMCs, a pocket with dimensions of $15 \mathrm{~mm} \times 15 \mathrm{~mm} \times$ $2.5 \mathrm{~mm}$ was machined within a $\mathrm{Cu}$ (purity 99.9\%) specimen. A proper amount of $99 \mathrm{Sn}-1 \mathrm{Cu}$ solder was placed in the pocket and reflowed in an oven. During reflow, a thermocouple was attached to the specimen to monitor its temperature. After reflow, the specimens were ground and polished to ensure that the top surface across the solder/Cu interface was smooth in one plane. The specimen after polishing is shown schematically in Fig. 2a.

The four specimens were then stored in an oven at temperature of $175^{\circ} \mathrm{C}$ to facilitate the perpendicular

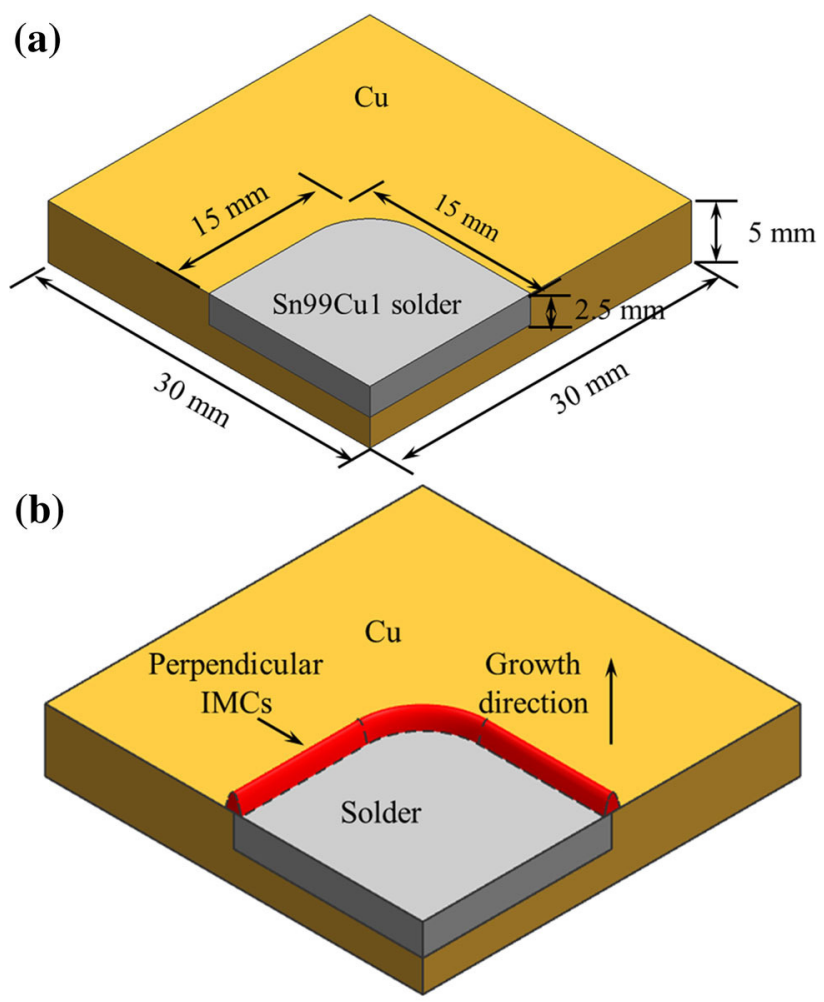

Fig. 2. Schematics of (a) specimen for characterizing perpendicular growth of IMCs and (b) perpendicular growth of IMCs (the red region) on the top surface of the specimen after aging.

growth of IMCs at the solder/Cu interface (as illustrated by the red region in Fig. 2b). After aging for every $168 \mathrm{~h}$ until $1132.5 \mathrm{~h}$, the specimens were removed from the oven after cooling. The height of the perpendicular IMCs on the polished top surface was then measured using a white-light interferometer (Zygo NewView 5000) at the same location for a given specimen. The areas of the scanned regions were no smaller than $1.5 \mathrm{~mm} \times 1.0 \mathrm{~mm}$ to ensure reliability of the obtained morphology of the specimens. The obtained surface morphology data were then converted into a series of profiles to calculate the average height of the perpendicular IMCs on the specimen.

After these measurements, SEM was used to examine the perpendicular IMCs from the top. FIB was also utilized to mill the specimen across the $99 \mathrm{Sn}-1 \mathrm{Cu} / \mathrm{Cu}$ interface to reveal the cross-section of the perpendicular IMCs after aging. However, milling the samples with FIB should be carefully planned as it could potentially introduce several types of artificial damage in the specimens: (1) the polished sample surface could be seriously damaged in a wide range during the milling and imaging with the ion beam in FIB; (2) the reliability of the measured heights of the perpendicular IMCs could be affected due to damage of the IMCs on the top surface; (3) the large hole in the sample and the fresh surface left by milling could lead to significant oxi-

\begin{tabular}{|l|lll|}
\hline & Journal : 11664_JEM & Dispatch : 18-9-2015 & Pages : 10 \\
& Article No.: $\mathbf{4 0 4 3}$ & $\square$ LE & $\square$ TYPESET \\
\hline
\end{tabular}


Perpendicular Growth Characteristics of Cu-Sn Intermetallic Compounds at the Surface of $99 \mathrm{Sn}-1 \mathrm{Cu} / \mathrm{Cu}$ Solder Interconnects

136 dation of the sample in subsequent aging. Hence, 137 after finishing all the aging and measurements, to minimize its potential influence on the reliability of the measured heights of the perpendicular IMCs.

\section{Planar Growth of IMCs}

For comparison with the perpendicular growth of IMCs on solder joints after aging, another set of $99 \mathrm{Sn}-1 \mathrm{Cu}$ solder was reflowed on polished $\mathrm{Cu}$ (purity $99.9 \%$ ) substrate using the same reflow conditions as in "Perpendicular Growth of IMCs" section, to investigate the planar growth of IMCs within solder joints. The six specimens were then stored in an oven at $175^{\circ} \mathrm{C}$ to promote the planar growth of IMCs after reflow. After aging for every $168 \mathrm{~h}$, the specimens were ground and polished to reveal the cross-section of the solder joint, as illustrated in Fig. 3. The interfacial $\mathrm{Cu}_{6} \mathrm{Sn}_{5}$ and $\mathrm{Cu}_{3} \mathrm{Sn}$ layers which grew along the interdiffusion direction were then revealed by etching with ethanol (80 vol.\%) and hydrochloric acid (20 vol.\%) solution. An Olympus BX60 M microscope was utilized for observation of the planar interfacial IMC layers. The interfaces between the solder, $\mathrm{Cu}_{6} \mathrm{Sn}_{5}, \mathrm{Cu}_{3} \mathrm{Sn}$, and $\mathrm{Cu}$ in the microscope images were fit with traces using Image-Pro image analysis software. Hence, the average thickness of a specific IMC layer could be derived by calculating the mean distance between two adjacent traces.

\section{Perpendicular Growth of IMCs}

The perpendicular IMCs on the $99 \mathrm{Sn}-1 \mathrm{Cu} / \mathrm{Cu}$ samples were examined by SEM and profiled with the Zygo NewView 5000 after aging for every $168 \mathrm{~h}$. Figure $4 \mathrm{a}$, c and e illustrates the morphological evolution of the perpendicular IMCs on the top surface of 99Sn-1Cu solder joints after progressively prolonged aging. Examples of surface profiles from the corresponding specimens are shown in Fig. $4 \mathrm{~b}, \mathrm{~d}$ and $\mathrm{f}$, leveled with the $\mathrm{Cu}$ part in the profile to remove the effect of the angle between the specimen and the instrument during scanning. Before aging,

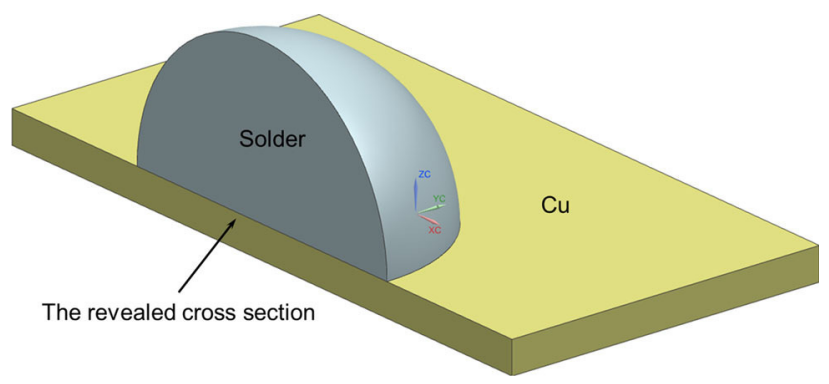

Fig. 3. Schematic of the specimen for investigating the planar growth of IMCs within $99 \mathrm{Sn}-1 \mathrm{Cu} / \mathrm{Cu}$ solder joints after aging at $175^{\circ} \mathrm{C}$

the surface of the $99 \mathrm{Sn}-1 \mathrm{Cu}$ solder joints was smooth across the solder/Cu interface after polishing, as illustrated in Fig. 4a. No perpendicular IMCs could be identified. Correspondingly, there is no notable peak at the solder/Cu interface in the surface profile in Fig. 4b. The height difference between the solder part and $\mathrm{Cu}$ surface was probably due to the higher polishing rate on the softer solder in comparison with the polishing rate on the $\mathrm{Cu}$ during sample preparation.

After aging at $175^{\circ} \mathrm{C}$ for $168 \mathrm{~h}$, a line of IMCs was observed to protrude out of the surface at the solder/ $\mathrm{Cu}$ interface, as shown in Fig. 4c. The spikes of the perpendicular IMCs can also be identified in the corresponding surface profile in Fig. 4d. The average height of the perpendicular IMCs can be estimated to be about $0.5 \mu \mathrm{m}$, with the $\mathrm{Cu}$ surface as reference. When the aging was extended to $1132.5 \mathrm{~h}$, the perpendicular IMCs grew significantly in both height and width, as illustrated in Fig. 4e, and the height of the perpendicular IMCs increased to approximately $1.5 \mu \mathrm{m}$ (Fig. 4f).

FIB was then utilized to reveal a cross-sectional view of the perpendicular IMCs at the solder/Cu interface after aging for $1132.5 \mathrm{~h}$ (Fig. 5). It is evident that the perpendicular IMCs on the sample surface were dendritic along several specific directions, which is different from the layer-type interfacial IMC layers within solder joints. Both $\mathrm{Cu}_{6} \mathrm{Sn}_{5}$ and $\mathrm{Cu}_{3} \mathrm{Sn}$ phases can be found in the perpendicular IMCs, with the $\mathrm{Cu}_{3} \mathrm{Sn}$ at the bottom of the dendrites close to the $\mathrm{Cu} / \mathrm{Cu}_{3} \mathrm{Sn}$ interface. The "root" of the perpendicular IMCs was a $\mathrm{Cu}$-rich region, so the $\mathrm{Cu}_{3} \mathrm{Sn}$ phase was probably produced before the formation of $\mathrm{Cu}_{6} \mathrm{Sn}_{5}$ in the initial perpendicular growth of IMCs, ${ }^{12-14}$ as discussed further in "Comparison of Growth Mechanisms" section below. Furthermore, it can also be observed that the $\mathrm{Cu}$ / $\mathrm{Cu}_{3} \mathrm{Sn}$ interface and $\mathrm{Cu}_{3} \mathrm{Sn} / \mathrm{Cu}_{6} \mathrm{Sn}_{5}$ interface in the planar IMCs shifted towards the $\mathrm{Cu}$ side near the sample surface. In contrast, the $\mathrm{Cu}_{6} \mathrm{Sn}_{5} /$ solder interface remained at a similar position within the same region.

The perpendicular IMCs on the sample surface were profiled using the Zygo NewView 5000 after aging. A series of surface profiles (grey region in Fig. 6a) could then be extracted from the obtained surface morphology across the solder/Cu interface, from which an average surface profile of the region could be derived (red profile in Fig. 6b). The height of the perpendicular IMCs was then evaluated by calculating the height difference between the peak and the $\mathrm{Cu}$ surface in the average profile of the scanned region. The relation between the heights of the perpendicular IMCs and the aging duration is plotted in Fig. 6b. Each data point in the figure represents the average height of the perpendicular IMCs from four specimens. It can be seen that the height of the perpendicular IMCs generally increased linearly with the square root of the aging duration, which can be expressed as

\begin{tabular}{|l|lll|}
\hline \multirow{2}{*}{ Journal : 11664_JEM } & Dispatch : $\mathbf{1 8 - 9 - 2 0 1 5}$ & Pages : $\mathbf{1 0}$ \\
& & $\square$ LE & $\square$ TYPESET \\
& Article No.: 4043 & $\square \mathrm{CP}$ & $\varangle$ DISK \\
\hline
\end{tabular}



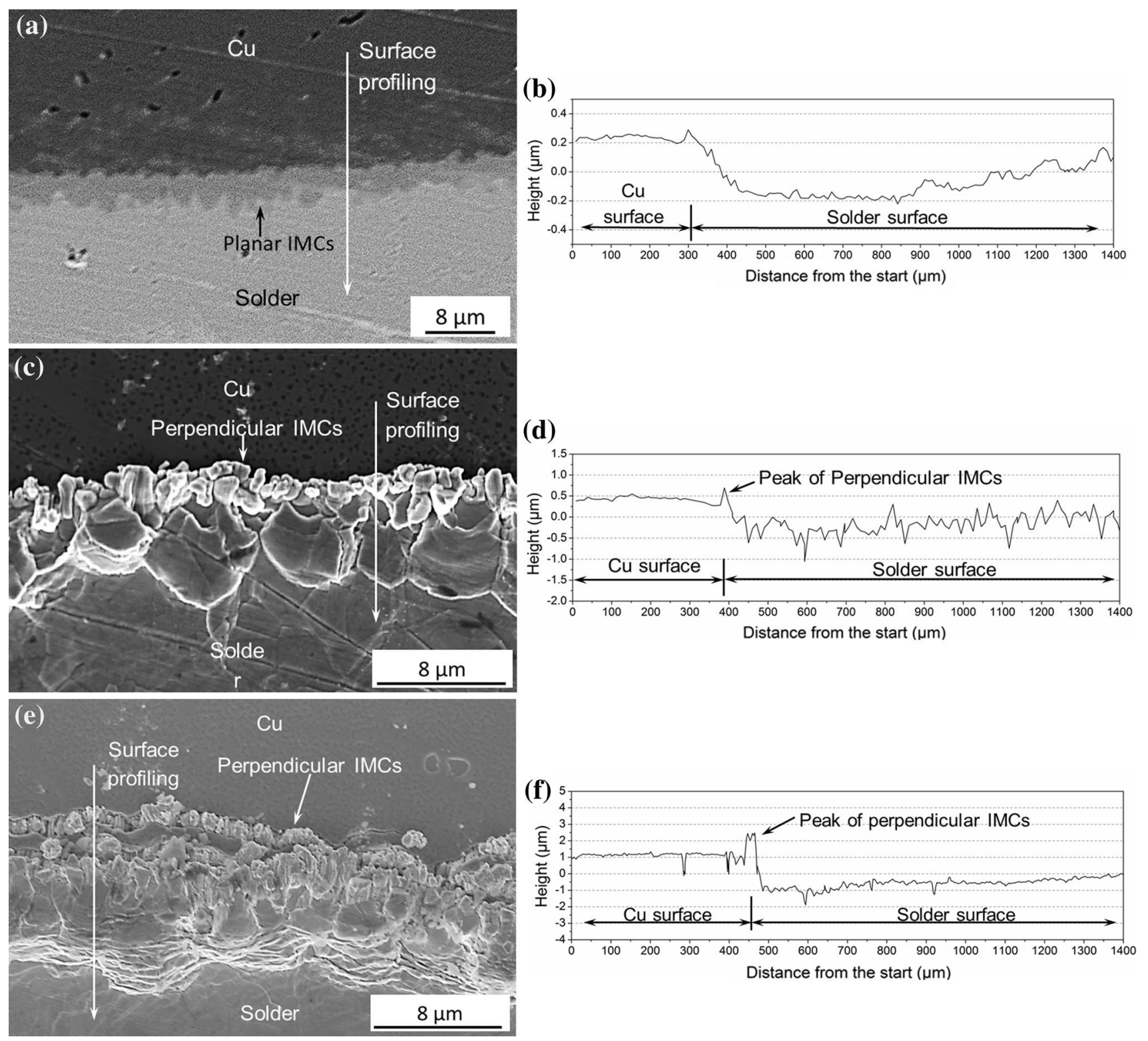

Fig. 4. Top views showing evolution of perpendicular IMCs after aging at $175^{\circ} \mathrm{C}$ for (a) $0 \mathrm{~h},(\mathrm{c}) 168 \mathrm{~h}$, and (e) $1132.5 \mathrm{~h}$, and (b, d, f) example surface profiles from corresponding specimens.

where $t$ is the aging duration in hours and $y$ is the height of the perpendicular IMCs in $\mu \mathrm{m}$. The parabolic correlation between the height of the perpendicular IMCs and the aging duration indicates that the perpendicular growth of the IMCs on the free surface of the solder joints is a diffusion-controlled process. ${ }^{15,16}$

\section{Planar Growth of IMCs}

For comparison, the planar growth of IMCs along the interdiffusion direction between the solder and $\mathrm{Cu}$ was also studied by aging and etching. Figure 7 shows a comparison of the planar IMCs in a 99Sn$1 \mathrm{Cu} / \mathrm{Cu}$ solder joint before aging and after aging at $175^{\circ} \mathrm{C}$ for $1006.5 \mathrm{~h}$. It can be observed that the interfacial IMC layers grew significantly, from about $5 \mu \mathrm{m}$ before aging to approximately $15 \mu \mathrm{m}$ after aging for $1006.5 \mathrm{~h}$. The morphology of the planar IMC layers also transformed from dendritic to layer type after aging.

Furthermore, only an interfacial $\mathrm{Cu}_{6} \mathrm{Sn}_{5}$ layer can be identified at the solder $/ \mathrm{Cu}$ interface in Fig. 7a. The absence of a $\mathrm{Cu}_{3} \mathrm{Sn}$ layer can be attributed to the insufficient reflow time for formation of an interfacial $\mathrm{Cu}_{3} \mathrm{Sn}$ layer before cooling ${ }^{17-19}$ or the low magnification of the microscope. After aging, the $\mathrm{Cu}_{6} \mathrm{Sn}_{5}$ layer thickened notably and a

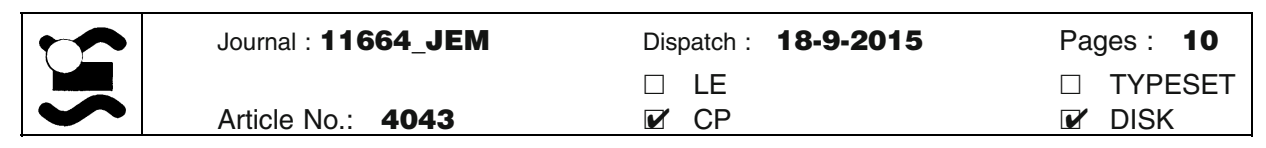


Perpendicular Growth Characteristics of Cu-Sn Intermetallic Compounds at the Surface of $99 \mathrm{Sn}-1 \mathrm{Cu} / \mathrm{Cu}$ Solder Interconnects

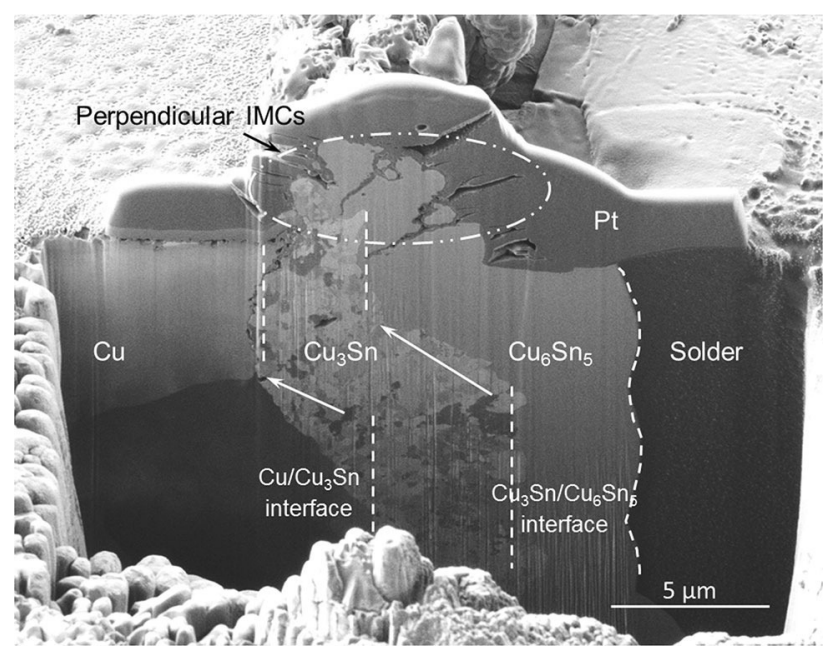

Fig. 5. Cross-sectional view of perpendicular IMCs at 99Sn-1Cu solder/Cu interface after aging at $175^{\circ} \mathrm{C}$ for $1132.5 \mathrm{~h}$. The platinum $(\mathrm{Pt})$ on the top was used to protect the materials beneath from damage by the ion beam during FIB milling.
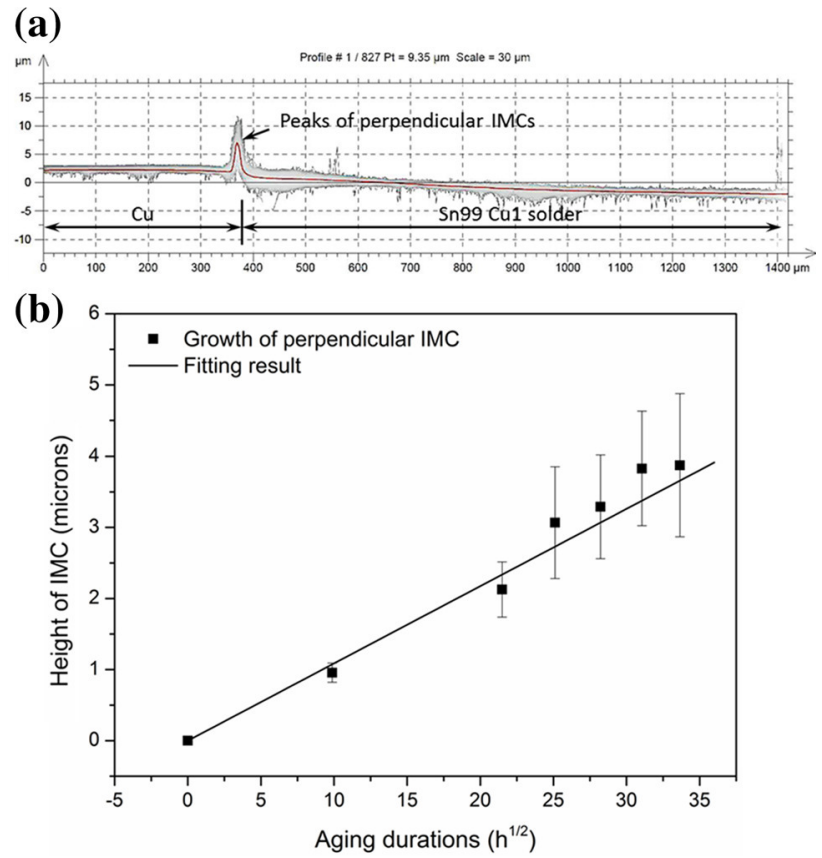

Fig. 6. Perpendicular growth of IMCs versus aging duration: (a) example series of surface profiles derived from the scanned region of a specimen, with the solid highlighted line as the mean value of the multiple measurements represented in the grey region; (b) average height of perpendicular IMCs versus the square root of aging duration.

layer of $\mathrm{Cu}_{3} \mathrm{Sn}$ was produced between the $\mathrm{Cu}_{6} \mathrm{Sn}_{5}$ layer and $\mathrm{Cu}$ substrate, as illustrated in Fig. $7 \mathrm{~b}$.

The thicknesses of the interfacial $\mathrm{Cu}_{6} \mathrm{Sn}_{5}, \mathrm{Cu}_{3} \mathrm{Sn}$, and entire IMC layers were measured using the method explained in "Planar Growth of IMCs" section and are plotted as a function of aging duration in Fig. 8. Each data point in the figure is the average thickness of six specimens, and the error bar
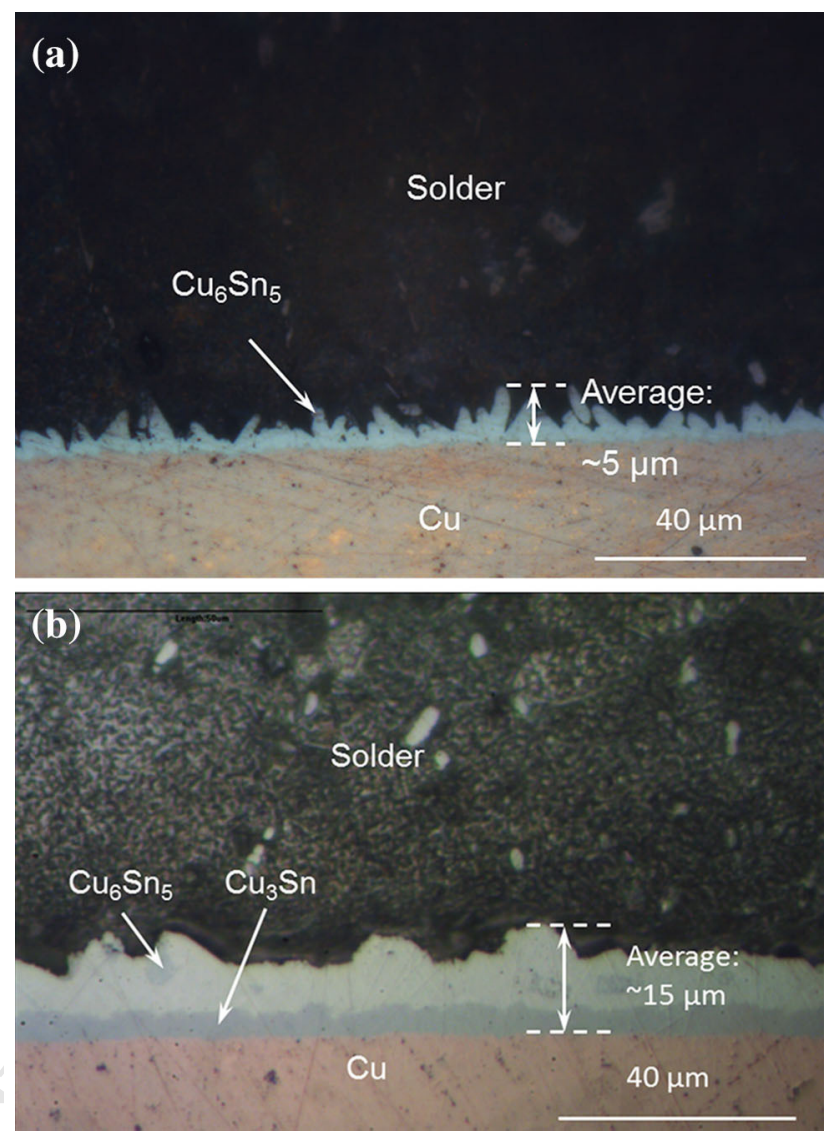

Fig. 7. Observation of planar IMC layers at the $99 \mathrm{Sn}-1 \mathrm{Cu}$ solder/Cu interface (a) before aging and (b) after aging at $175^{\circ} \mathrm{C}$ for $1006.5 \mathrm{~h}$.

indicates the standard deviation of the measurements. The linear fitting was based on the understanding that the planar growth of interfacial IMC layers is primarily dominated by the opposing diffusion of $\mathrm{Sn}$ and $\mathrm{Cu}$ atoms during aging, following a parabolic law with aging duration. ${ }^{20}$ Figure 8 shows that the curve fitting result is a close approximation to the measured thickness of the interfacial IMC layers after increasing aging durations, and the relation can be expressed as

$$
\begin{aligned}
& h_{\mathrm{IMC}}=0.27 \sqrt{t+4.6}, \\
& h_{\mathrm{Cu} 6 \mathrm{Sn} 5}=0.16 \sqrt{t+4.1} \text { and } h_{\mathrm{Cu} 3 \mathrm{Sn}}=0.17 \sqrt{t},
\end{aligned}
$$

where $t$ is the aging duration in hours and $h$ is the thickness of each layer in $\mu \mathrm{m}$. In comparison with the diffusion coefficients reported in Ref. 20, the value obtained in this work is within a reasonable range. Equation 2 also implies that the planar growth of IMCs is governed by the interdiffusion between the solder and $\mathrm{Cu}$ during aging. ${ }^{15,16}$ The constants in this equation, 4.6 and 4.1, indicate the initial thickness of the IMC layer before aging. They are supposed to be the same, since only a $\mathrm{Cu}_{6} \mathrm{Sn}_{5}$ layer can be observed before aging (Fig. 7a)). The minor variation between them could be due to error

\begin{tabular}{|l|lll|}
\hline Journal : 11664_JEM & Dispatch : $\mathbf{1 8 - 9 - 2 0 1 5}$ & Pages : 10 \\
& & $\square$ LE & $\square$ TYPESET \\
& Article No.: $\mathbf{4 0 4 3}$ & $\square$ CP & $\square$ DISK \\
\hline
\end{tabular}




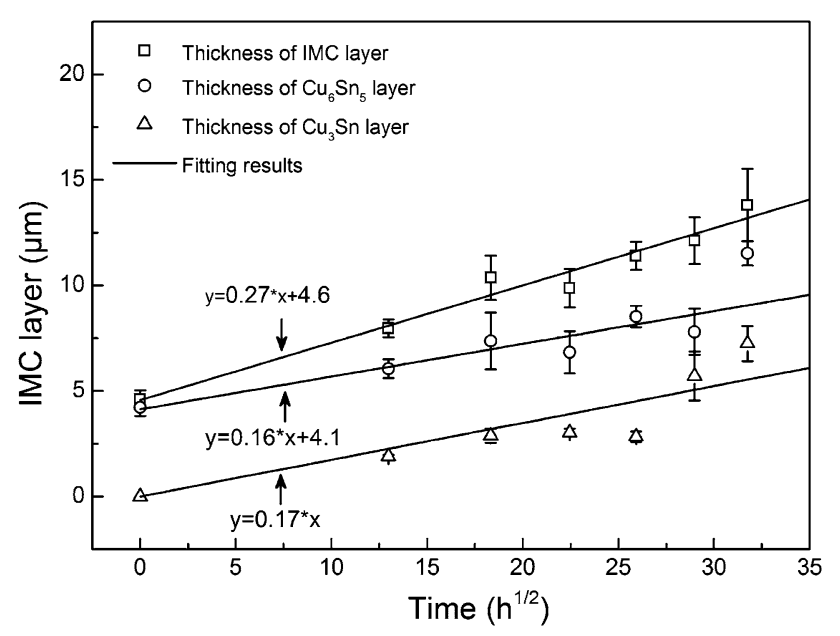

Fig. 8. Correlation between growth of interfacial IMC layers and aging duration at $175^{\circ} \mathrm{C}$.

in the measurements and curve fitting. From Fig. 8, it can also be found that the thickness of the interfacial $\mathrm{Cu}_{3} \mathrm{Sn}$ and $\mathrm{Cu}_{6} \mathrm{Sn}_{5}$ layers did not follow a strict linear relation with the aging duration. This can be ascribed to the deviation in the measurement and the different initial states of the sites randomly chosen for measurement.

\section{DISCUSSION}

As presented in "Results" section, both perpendicular and planar growth of IMCs occurred at the solder/Cu interface, depending on the opposing interdiffusion of $\mathrm{Sn}$ and $\mathrm{Cu}$ atoms during aging. However, there are several differences between the growth of the IMCs in these two directions.

\section{Movement of $\mathrm{Cu}_{3} \mathrm{Sn} / \mathrm{Cu}_{6} \mathrm{Sn}_{5}$ and $\mathrm{Cu}_{3} \mathrm{Sn} / \mathrm{Cu}$ Interfaces}

The cross-section of the $99 \mathrm{Sn}-1 \mathrm{Cu} / \mathrm{Cu}$ solder joint revealed by FIB illustrates that the $\mathrm{Cu}_{6} \mathrm{Sn}_{5} / \mathrm{Cu}_{3} \mathrm{Sn}$ and $\mathrm{Cu} / \mathrm{Cu}_{3} \mathrm{Sn}$ interfaces moved towards the $\mathrm{Cu}$ side near the surface of the $99 \mathrm{Sn}-1 \mathrm{Cu} / \mathrm{Cu}$ solder joint, as shown in Fig. 5. In contrast, the $\mathrm{Cu}_{6} \mathrm{Sn}_{5} /$ solder interface remained relatively more consistently within the same region. This shift of the $\mathrm{Cu}_{6} \mathrm{Sn}_{5} /$ $\mathrm{Cu}_{3} \mathrm{Sn}$ and $\mathrm{Cu} / \mathrm{Cu}_{3} \mathrm{Sn}$ interfaces leads to significant expansion of the $\mathrm{Cu}_{6} \mathrm{Sn}_{5}$ layer and a decrease in the thickness of the $\mathrm{Cu}_{3} \mathrm{Sn}$ layer. Given the compositions of the $\mathrm{Sn}$ and $\mathrm{Cu}$ elements in these two types of IMC, it can be deduced that the concentration of Sn grows remarkably near the free surface of the solder joint.

In the region close to the sample surface, both bulk and surface diffusion of Sn atoms can contribute to the movement of Sn atoms during aging. However, for the region farther from the surface, Sn atoms can only move by bulk diffusion. Therefore, the increase in the Sn concentration near the sample surface indicates that the surface diffusion of Sn atoms is much faster than their bulk diffusion in solder joints, which obeys the general observation that surface diffusion is faster than bulk diffusion. ${ }^{21,22}$

Furthermore, this increase of the concentration of $\mathrm{Sn}$ also indicates a drop in the fraction of $\mathrm{Cu}$ atoms near the surface of the solder joints. Because the major diffusion mechanism for both $\mathrm{Cu}$ and $\mathrm{Sn}$ atoms is surface diffusion in this region, it is reasonable to conclude that the surface diffusion of $\mathrm{Sn}$ atoms is much faster than the surface diffusion of $\mathrm{Cu}$ atoms. Otherwise, the $\mathrm{Cu}$-rich $\mathrm{Cu}_{3} \mathrm{Sn}$ phase would expand instead of the Sn-rich $\mathrm{Cu}_{6} \mathrm{Sn}_{5}$ phase and the $\mathrm{Cu}_{3} \mathrm{Sn} / \mathrm{Cu}_{6} \mathrm{Sn}_{5}$ interface and $\mathrm{Cu}_{6} \mathrm{Sn}_{5} /$ solder interface would move towards the solder side near the sample surface.

\section{Comparison of Growth Mechanisms}

For the planar growth of IMCs in solder joints, the IMC layers at the solder/Cu interface are normally formed during reflow. Although the existence of a $\mathrm{Cu}_{3} \mathrm{Sn}$ layer in $\mathrm{Sn}$-based solder/Cu solder joints after reflow remains controversial, it is generally accepted that the formation of $\mathrm{Cu}_{6} \mathrm{Sn}_{5}$ and $\mathrm{Cu}_{3} \mathrm{Sn}$ is not simultaneous, with the former being prior to the latter. ${ }^{23-26}$ In contrast, in perpendicular IMCs, the $\mathrm{Cu}_{3} \mathrm{Sn}$ is produced first, followed by the formation of $\mathrm{Cu}_{6} \mathrm{Sn}_{5}$. These opposite formation sequences of $\mathrm{Cu}_{6} \mathrm{Sn}_{5}$ and $\mathrm{Cu}_{3} \mathrm{Sn}$ in the perpendicular and planar IMCs can be primarily attributed to the different proportions of $\mathrm{Sn}$ and $\mathrm{Cu}$ atoms in the corresponding regions.

The initial formation of a planar $\mathrm{Cu}_{6} \mathrm{Sn}_{5}$ layer in a solder joint (i.e., a $99 \mathrm{Sn}-1 \mathrm{Cu} / \mathrm{Cu}$ solder joint in this work) relies on the reaction between liquid solder and $\mathrm{Cu}$ during reflow. When the liquid solder is in contact with solid $\mathrm{Cu}, \mathrm{Cu}_{6} \mathrm{Sn}_{5}$ is generated quickly due to the comparable concentration of $\mathrm{Sn}$ and $\mathrm{Cu}$ atoms in a localized region until the $\mathrm{Cu}_{6} \mathrm{Sn}_{5}$ layer covers the entire solder/Cu interface ${ }^{27}$ (Fig. 9a). The growth of $\mathrm{Cu}_{6} \mathrm{Sn}_{5}$ in subsequent aging is primarily based on the reaction $6 \mathrm{Cu}+5 \mathrm{Sn} \rightarrow \mathrm{Cu}_{6} \mathrm{Sn}_{5} \cdot{ }^{28}$

The growth of $\mathrm{Cu}_{3} \mathrm{Sn}$ in planar IMCs during aging can be attributed to two possible mechanisms: the reaction between $\mathrm{Sn}$ and $\mathrm{Cu}\left(3 \mathrm{Cu}+\mathrm{Sn} \rightarrow \mathrm{Cu}_{3} \mathrm{Sn}\right)$ and the transformation of $\mathrm{Cu}_{6} \mathrm{Sn}_{5} \quad\left(\mathrm{Cu}_{6} \mathrm{Sn}_{5}+\right.$ $\left.9 \mathrm{Cu} \rightarrow 5 \mathrm{Cu}_{3} \mathrm{Sn}\right){ }^{29}$ Both mechanisms suggest that the formation of a $\mathrm{Cu}_{3} \mathrm{Sn}$ layer requires a $\mathrm{Cu}$-enriched region. ${ }^{30}$ Therefore, a $\mathrm{Cu}_{3} \mathrm{Sn}$ layer can only be produced when the concentration of $\mathrm{Sn}$ is low enough at the $\mathrm{Cu}_{6} \mathrm{Sn}_{5} / \mathrm{Cu}$ interface. This can happen only after the thickness of the interfacial $\mathrm{Cu}_{6} \mathrm{Sn}_{5}$ layer exceeds a certain threshold and the number of free $\mathrm{Sn}$ atoms near the $\mathrm{Cu}$ side is sufficiently reduced by the increasing diffusion distance (Fig. 9b). Therefore, the formation of $\mathrm{Cu}_{3} \mathrm{Sn}$ is always after the formation of $\mathrm{Cu}_{6} \mathrm{Sn}_{5}$ in planar growth of IMCs (Fig. 9c). The subsequent growth of $\mathrm{Cu}_{3} \mathrm{Sn}$ can be attributed to the decomposition of $\mathrm{Cu}_{6} \mathrm{Sn}_{5}$ due to the

\begin{tabular}{|l|lll|}
\hline & Journal : 11664_JEM & Dispatch : 18-9-2015 & Pages : 10 \\
& Article No.: $\mathbf{4 0 4 3}$ & $\square$ LE & $\square$ TYPESET \\
\hline
\end{tabular}


Perpendicular Growth Characteristics of Cu-Sn Intermetallic Compounds at the Surface of $99 \mathrm{Sn}-1 \mathrm{Cu} / \mathrm{Cu}$ Solder Interconnects

(a)

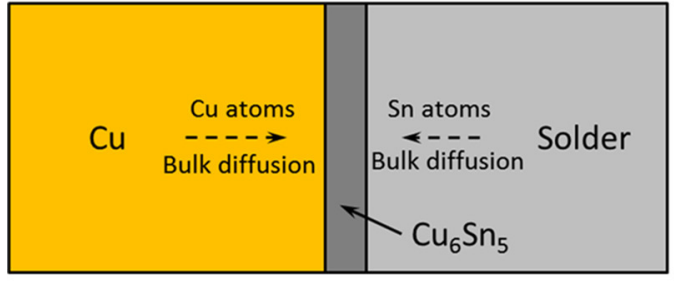

(c)

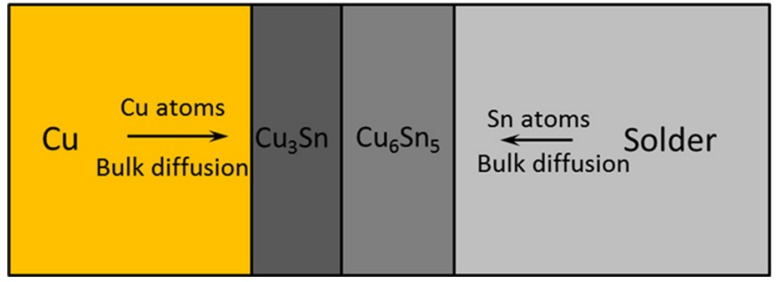

(b)

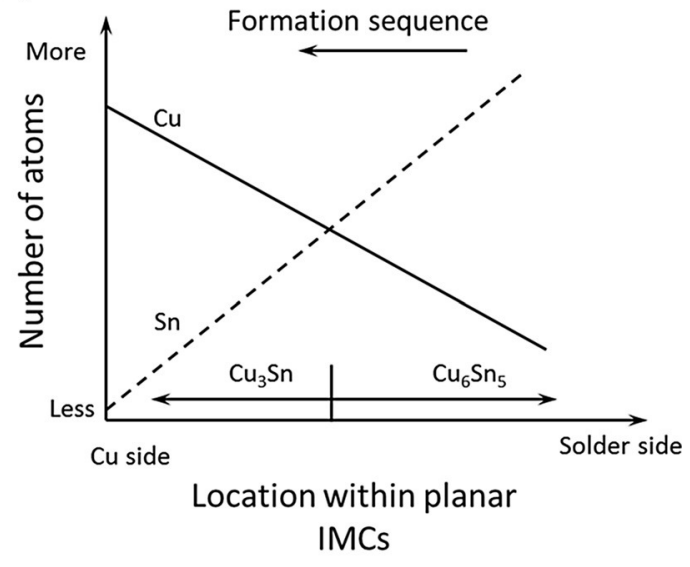

Fig. 9. Schematic of growth characteristics of planar IMCs: (a) formation of initial $\mathrm{Cu}_{6} \mathrm{Sn}_{5}$ phase; (b) distribution of free $\mathrm{Sn}$ and $\mathrm{Cu}$ atoms at the interface due to diffusion process; (c) formation of $\mathrm{Cu}_{3} \mathrm{Sn}$ at the $\mathrm{Cu}_{6} \mathrm{Sn}_{5} / \mathrm{Cu}$ interface due to higher concentration of $\mathrm{Cu}$.

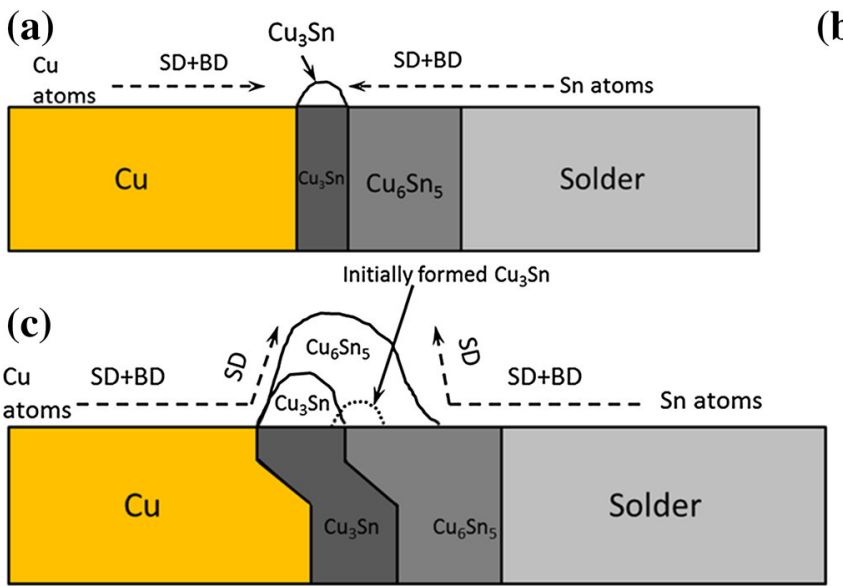

(b)

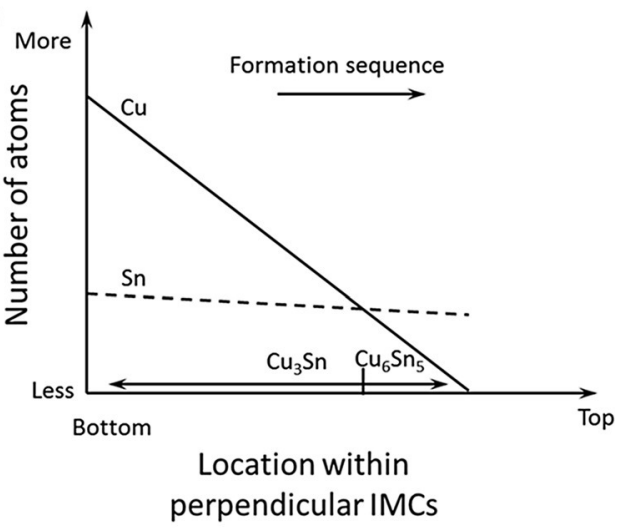

Fig. 10. Formation of $\mathrm{Cu}_{3} \mathrm{Sn}$ and $\mathrm{Cu}_{6} \mathrm{Sn}_{5}$ in perpendicular IMCs: (a) formation of $\mathrm{Cu}_{3} \mathrm{Sn}$ and diffusion at the beginning of aging; (b) schematic illustration of the number of free $\mathrm{Sn}$ and $\mathrm{Cu}$ atoms within perpendicular IMCs from the bottom to top; (c) formation of $\mathrm{Cu}_{6} \mathrm{Sn}_{5}$ after $\mathrm{Cu}_{3} \mathrm{Sn}_{\mathrm{Srows}}$ to a certain height and movement of $\mathrm{Cu}_{6} \mathrm{Sn}_{5} / \mathrm{Cu}_{3} \mathrm{Sn}$ and $\mathrm{Cu}_{3} \mathrm{Sn} / \mathrm{Cu}$ interfaces towards the $\mathrm{Cu}$ side. (SD: surface diffusion, BD: bulk diffusion).

lack of $\mathrm{Sn}$ atoms at the $\mathrm{Cu}_{6} \mathrm{Sn}_{5} / \mathrm{Cu}_{3} \mathrm{Sn}$ interface and the possible reaction between $\mathrm{Sn}$ and $\mathrm{Cu}$ atoms at the $\mathrm{Cu} / \mathrm{Cu}_{3} \mathrm{Sn}$ interface. ${ }^{29}$

In contrast, the perpendicular growth of IMCs starts at the $\mathrm{Cu}$ side in the $99 \mathrm{Sn}-1 \mathrm{Cu} / \mathrm{Cu}$ solder joint during aging (as shown in Figs. 4c and 5), which is probably due to the faster surface diffusion of Sn atoms as suggested in "Movement of $\mathrm{Cu}_{3} \mathrm{Sn} / \mathrm{Cu}_{6} \mathrm{Sn}_{5}$ and $\mathrm{Cu}_{3} \mathrm{Sn} / \mathrm{Cu}$ Interfaces" section. At the beginning of the perpendicular growth of the IMCs, the distance for diffusion of $\mathrm{Cu}$ atoms is negligible. However, Sn atoms need to diffuse through the entire planar $\mathrm{Cu}_{6} \mathrm{Sn}_{5}$ layer and a part of the planar $\mathrm{Cu}_{3} \mathrm{Sn}$ layer to react with $\mathrm{Cu}$ atoms. Therefore, the proportion of $\mathrm{Cu}$ atoms is much higher than the proportion of $\mathrm{Sn}$ atoms in the region where perpendicular IMCs start growing. This $\mathrm{Cu}$-rich region can lead to the formation and growth of
$\mathrm{Cu}_{3} \mathrm{Sn}\left(\mathrm{Cu}+3 \mathrm{Sn} \rightarrow \mathrm{Cu}_{3} \mathrm{Sn}\right)$ before production of any $\mathrm{Cu}_{6} \mathrm{Sn}_{5}$ (Fig. 10a) during aging, as reported by other researchers. ${ }^{12-14}$

After the initial formation of $\mathrm{Cu}_{3} \mathrm{Sn}$, the subsequent perpendicular growth of IMCs can be divided into two directions: the height direction and the width direction. For the height direction, when the $\mathrm{Sn}$ atoms reach the root of the perpendicular IMCs by diffusion, a part of the $\mathrm{Sn}$ can react with $\mathrm{Cu}$ atoms $\left(\mathrm{Cu}+\mathrm{Sn} \rightarrow \mathrm{Cu}_{3} \mathrm{Sn}\right)$ to contribute to the perpendicular growth of the $\mathrm{Cu}_{3} \mathrm{Sn}$ phase. However, the $\mathrm{Sn}$ and $\mathrm{Cu}$ atoms are not necessarily completely consumed by this reaction, because of the high activation energy required for formation of $\mathrm{Cu}_{3} \mathrm{Sn}^{31,32}$ Hence, the rest of the $\mathrm{Sn}$ and $\mathrm{Cu}$ atoms, possibly the majority of them, are able to move further to the frontier of the perpendicular $\mathrm{Cu}_{3} \mathrm{Sn}$ by surface diffusion (and possibly a minor part of

\begin{tabular}{|l|lll|}
\hline & Journal : 11664_JEM & Dispatch : 18-9-2015 & Pages : 10 \\
& Article No.: $\mathbf{4 0 4 3}$ & $\square$ LE & $\square$ TYPESET \\
\hline
\end{tabular}


430 bulk diffusion because of the small volume of $\mathrm{Cu}_{3} \mathrm{Sn}$ 431 present). The distance for diffusion of free $\mathrm{Sn}$ and $432 \mathrm{Cu}$ atoms along the height direction increases with 433 the perpendicular growth of the $\mathrm{Cu}_{3} \mathrm{Sn}$ present. As 434 discussed in "Movement of $\mathrm{Cu}_{3} \mathrm{Sn} / \mathrm{Cu}_{6} \mathrm{Sn}_{5}$ and $435 \mathrm{Cu}_{3} \mathrm{Sn} / \mathrm{Cu}$ Interfaces" section, the surface diffusion 436 of $\mathrm{Cu}$ atoms is much slower in comparison with the 437 surface diffusion of Sn atoms. Hence, with the per438 pendicular growth of the IMCs, the number of free $439 \mathrm{Cu}$ atoms in the perpendicular IMCs decreases 440 much faster than the number of Sn atoms (as illustrated in Fig. 10b). This can result in a drop in the concentration of free $\mathrm{Cu}$ atoms at the frontier of the perpendicular $\mathrm{Cu}_{3} \mathrm{Sn}$. When the perpendicular $\mathrm{Cu}_{3} \mathrm{Sn}$ is high enough and the diffusion distance for $\mathrm{Sn}$ and $\mathrm{Cu}$ atoms reaches a certain value, the fractions of $\mathrm{Cu}$ and $\mathrm{Sn}$ atoms become comparable. This can then lead to the formation and growth of $\mathrm{Cu}_{6} \mathrm{Sn}_{5}$ at the top of the perpendicular IMCs $\left(6 \mathrm{Cu}+5 \mathrm{Sn} \rightarrow \mathrm{Cu}_{6} \mathrm{Sn}_{5}\right)$ (Fig. 10c). Hence, the formation of $\mathrm{Cu}_{6} \mathrm{Sn}_{5}$ can only happen after the formation and growth of $\mathrm{Cu}_{3} \mathrm{Sn}$ in the perpendicular IMCs in the height direction.

In the width direction, the $\mathrm{Cu}_{6} \mathrm{Sn}_{5} / \mathrm{Cu}_{3} \mathrm{Sn}$ interface in the planar IMCs moves towards the $\mathrm{Cu}_{3} \mathrm{Sn}$ side (Figs. 5 and 10c) near the sample surface due to the much faster surface diffusion of Sn atoms during aging. Because of the greater supply of Sn atoms in comparison with the supply of $\mathrm{Cu}$, a part of or even the entire $\mathrm{Cu}$-rich $\mathrm{Cu}_{3} \mathrm{Sn}$ phase present could be gradually transformed to $\mathrm{Sn}$-rich $\mathrm{Cu}_{6} \mathrm{Sn}_{5}$ phase $\left(2 \mathrm{Cu}_{3} \mathrm{Sn}+3 \mathrm{Sn} \rightarrow \mathrm{Cu}_{6} \mathrm{Sn}_{5}\right)^{33}$ in both perpendicular IMCs (illustrated by the $\mathrm{Cu}_{3} \mathrm{Sn}$ phase in dashed lines in Fig. 10c) and the planar IMCs near the sample surface. This decomposition of the $\mathrm{Cu}_{3} \mathrm{Sn}$ phase could also happen at the $\mathrm{Cu}_{6} \mathrm{Sn}_{5} / \mathrm{Cu}_{3} \mathrm{Sn}$ interface in the perpendicular IMCs to facilitate growth of $\mathrm{Cu}_{6} \mathrm{Sn}_{5}$ along the height direction. On the other hand, the $\mathrm{Cu}_{3} \mathrm{Sn} / \mathrm{Cu}$ interface in the planar IMCs also moves towards the $\mathrm{Cu}$ side near the sample surface because of the faster surface diffusion of $\mathrm{Sn}$ atoms. New $\mathrm{Cu}_{3} \mathrm{Sn}$ can also be produced near the new $\mathrm{Cu}_{3} \mathrm{Sn} / \mathrm{Cu}$ interface by the reaction $3 \mathrm{Cu}+\mathrm{Sn} \rightarrow \mathrm{Cu}_{3} \mathrm{Sn}$ in both the planar and perpendicular IMCs (Fig. 10c), since this is a $\mathrm{Cu}$-rich region.

\section{Comparison of Growth Rates}

A comparison of the growth rates of the perpendicular and planar IMCs is illustrated in Fig. 11. It is evident that the perpendicular growth of IMCs is much slower than the planar growth of interfacial IMC layers. Consequently, the thickness of the planar IMCs after aging is several times greater than the height of the perpendicular IMCs after aging for similar periods.

The lower growth rate of the perpendicular IMCs can be primarily ascribed to the longer diffusion distance of $\mathrm{Sn}$ and $\mathrm{Cu}$ atoms and the limited and decreasing supply of both $\mathrm{Sn}$ and $\mathrm{Cu}$ atoms in the perpendicular growth, though the surface diffusion

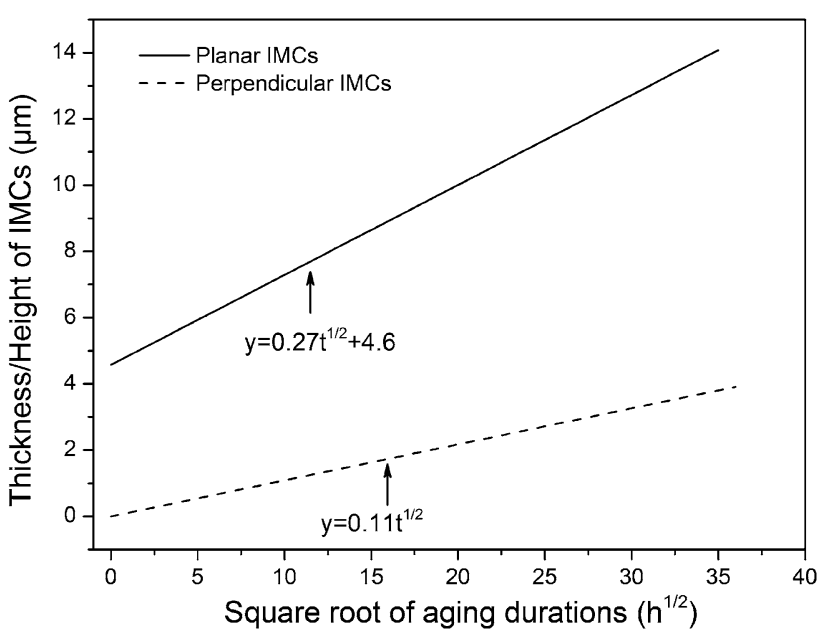

Fig. 11. Comparison of perpendicular and planar growth of IMCs at the solder/Cu interface during aging at $175^{\circ} \mathrm{C}$.

of $\mathrm{Cu}$ and $\mathrm{Sn}$ that contributes to the perpendicular growth of IMCs is believed to be much faster than their bulk diffusion in the planar growth.

For the perpendicular growth of IMCs, the sum diffusion distance of both $\mathrm{Sn}$ and $\mathrm{Cu}$ atoms generally consist of the thickness of the planar IMC layers and the height of the perpendicular IMCs, $D_{\text {perpendicular }}=H_{\text {planar }} \quad$ IMCs $+H_{\text {perpendicular }}$ IMCs , where $D_{\text {perpendicular }}$ is the sum diffusion distance of both $\mathrm{Sn}$ and $\mathrm{Cu}$ for the perpendicular growth of IMCs, $H_{\text {planar IMCs }}$ is the thickness of the planar IMC layers, and $H_{\text {perpendicular IMCs }}$ is the height of the perpendicular IMCs. However, for the planar growth of IMCs within the solder joint, the total diffusion distance for both $\mathrm{Sn}$ and $\mathrm{Cu}$ atoms is the thickness of the planar IMC layers, $D_{\text {planar }}=$ $H_{\text {planar IMCs, where }} D_{\text {planar }}$ is the sum diffusion distance of both $\mathrm{Sn}$ and $\mathrm{Cu}$ atoms for planar growth of IMCs. Due to the additional height of the perpendicular IMCs ( $\left.H_{\text {perpendicular IMCs }}\right)$ in the diffusion path, it is reasonable to conclude that the diffusion distance for perpendicular growth of IMCs is always longer than the diffusion path for planar growth of IMCs, $D_{\text {perpendicular }}>D_{\text {planar. }}$.

The available free $\mathrm{Sn}$ and $\mathrm{Cu}$ atoms for producing the two types of IMCs can also significantly affect the growth rates along the two directions. The supply of $\mathrm{Sn}$ and $\mathrm{Cu}$ atoms in the planar growth of IMCs basically relies on the opposing diffusion from the adjacent solder and $\mathrm{Cu}$ substrate at the two sides of the IMC layers (as illustrated in Fig. 9c), which can be regarded as infinite. However, for the perpendicular growth of IMCs, the $\mathrm{Sn}$ and $\mathrm{Cu}$ atoms need to pass the planar IMC layers by surface diffusion and bulk diffusion before they can reach the root of the perpendicular IMCs (Fig. 10a). During diffusion, both $\mathrm{Sn}$ and $\mathrm{Cu}$ atoms can possibly be captured by the reactions that contribute to the planar growth of IMCs, particularly the Sn atoms from the solder side. The significant expansion of

\begin{tabular}{|l|lll|}
\hline & Journal : 11664_JEM & Dispatch : 18-9-2015 & Pages : 10 \\
& & $\square$ LE & $\square$ TYPESET \\
\hline Article No.: 4043 & $\square$ CP & $\square$ DISK \\
\hline
\end{tabular}


Perpendicular Growth Characteristics of Cu-Sn Intermetallic Compounds at the Surface of $99 \mathrm{Sn}-1 \mathrm{Cu} / \mathrm{Cu}$ Solder Interconnects

529 the planar $\mathrm{Cu}_{6} \mathrm{Sn}_{5}$ layer near the sample surface in 530 Fig. 5 can be attributed to $\mathrm{Sn}$ atoms captured dur531 ing surface diffusion from the solder to the bottom of 532 the perpendicular IMCs. Hence, unlike the infinite 533 supply of $\mathrm{Sn}$ and $\mathrm{Cu}$ atoms in the planar growth of 534 IMCs, the supply of free atoms to the perpendicular 535 growth of IMCs is limited.

536

After the $\mathrm{Sn}$ and $\mathrm{Cu}$ atoms reach the root of the perpendicular IMCs, they need to diffuse further from the bottom to the top (Fig. 10c), so that the height of the perpendicular IMCs can grow during aging. Because of the increasing diffusion distance due to the perpendicular growth of the IMCs, the numbers of free $\mathrm{Sn}$ and $\mathrm{Cu}$ atoms that can contribute to the perpendicular growth drop continuously during aging, as illustrated in Fig. $10 \mathrm{~b}$. Consequently, the limited and decreasing number of available $\mathrm{Sn}$ and $\mathrm{Cu}$ atoms can significantly retard the perpendicular growth of IMCs during aging, which is different from the planar growth of IMCs.

\section{Potential Effects of Perpendicular Growth of IMCs}

It has been reported that the growth of $\mathrm{Cu}_{6} \mathrm{Sn}_{5}$ and $\mathrm{Cu}_{3} \mathrm{Sn}$ during aging can induce stress evolution within interfacial IMC layers due to volume shrinkage resulting from the density increase in solid-state reactions. ${ }^{34}$ It is reasonable to assume that the growth of planar IMC layers in this work can also induce build-up of residual stress during aging. Similar to the effect of the growth of Sn whiskers, ${ }^{35}$ perpendicular growth of IMCs may partly release this residual stress at the solder/Cu interface. ${ }^{35}$ On the other hand, the residual stress in solder joints may also facilitate the perpendicular growth of IMCs, based on the suggestion that the perpendicular IMCs in solder joints after electromigration tests were "squeezed out" by compressive stress. ${ }^{9,10}$ However, the effect of the stress on the planar growth of IMCs remains uncertain, deserving further study.

Similar to the effect of Sn whiskers, perpendicular growth of IMCs can also possibly lead to failure of fine-pitch packages. In electronic packages, though there is no specifically prepared free surface, the perpendicular IMCs can still grow into the gap between two adjacent solder joints, which is perpendicular to the diffusion direction. When the pitch is reduced below $50 \mu \mathrm{m}$ (as in three-dimensional packages), the gap between two adjacent microbumps is only $10 \mu \mathrm{m}$ to $20 \mu \mathrm{m} .{ }^{36,37}$ In this case, perpendicular growth of IMCs is very likely to lead to shorts, which could be worse if the packaging density increases further in the future. Furthermore, protruding IMCs could be fractured into particles under vibration or mechanical loads. These loose IMC particles are also harmful to device reliability.

The risk of shorts due to perpendicular IMCs can be minimized by underfilling. It has been suggested that void-free encapsulation, such as conventional flip-chip underfill, can well suppress growth of Sn whiskers to prevent electrical shorts. ${ }^{38}$ This means that good encapsulation can also retard perpendicular growth of IMCs to prevent the resulting shorts. However, if the packaging density increases further, the decreasing gap between two adjacent microbumps could possibly bring significant challenges in achieving void-free encapsulation $^{39}$ and promote the possibility of electrical shorts. Hence, the perpendicular growth of IMCs should be further investigated in the future.

\section{CONCLUSIONS}

Planar and perpendicular growth of Cu-Sn IMCs in $99 \mathrm{Sn}-1 \mathrm{Cu} / \mathrm{Cu}$ solder joints were studied after aging. From the cross-sectional views of perpendicular IMCs revealed by FIB, it was found that the morphology of the perpendicular IMCs was dendritic, which is different from the layer-type planar IMCs. Furthermore, the $\mathrm{Cu} / \mathrm{Cu}_{3} \mathrm{Sn}$ and $\mathrm{Cu}_{3} \mathrm{Sn} /$ $\mathrm{Cu}_{6} \mathrm{Sn}_{5}$ interfaces within the solder joint moved towards the $\mathrm{Cu}$ side near the sample surface, which can be ascribed to faster surface diffusion of $\mathrm{Sn}$ atoms within this region.

The formation sequence of $\mathrm{Cu}_{6} \mathrm{Sn}_{5}$ and $\mathrm{Cu}_{3} \mathrm{Sn}$ in the perpendicular IMCs was also found to be opposite to that in planar IMC layers within solder joints. In perpendicular IMCs, the formation of $\mathrm{Cu}_{3} \mathrm{Sn}$ is prior to the formation of $\mathrm{Cu}_{6} \mathrm{Sn}_{5}$, because of the high concentration of $\mathrm{Cu}$ atoms where the perpendicular growth of IMCs starts. However, the $\mathrm{Cu}_{6} \mathrm{Sn}_{5}$ is believed to form before the $\mathrm{Cu}_{3} \mathrm{Sn}$ in planar interfacial IMC layers, since a $\mathrm{Cu}$-rich region is required to produce $\mathrm{Cu}_{3} \mathrm{Sn}$ in planar IMC layers.

Both the planar and perpendicular growth of IMCs follow a parabolic law with aging duration, indicating that the growth was dominated by interdiffusion of $\mathrm{Sn}$ and $\mathrm{Cu}$ atoms during aging. However, the perpendicular growth of IMCs was much slower than the planar growth of IMCs. This can be attributed to the longer diffusion distance and the limited supply of $\mathrm{Sn}$ and $\mathrm{Cu}$ atoms in the perpendicular growth of IMCs during aging.

\section{ACKNOWLEDGEMENTS}

Z.C. would like to acknowledge the joint $\mathrm{PhD}$ programme between Loughborough University (UK) and Huazhong University of Science and Technology (China). This research was also supported by a Marie Curie International Research Staff Exchange Scheme Project within the 7th European Community Framework Programme, No. PIRSES-GA-2010269113, entitled "Micro-Multi-Material Manufacture to Enable Multifunctional Miniaturised Devices (M6)," as well as the National Natural Science Foundation of China (No. 60976076).

\section{REFERENCES}

1. Y. Ping-Feng, L. Yi-Shao, S.-R. Jian, and C. Jiunn, 8th International Conference on Electronic Packaging Technology, Shanghai, 14-17 August, 2007, pp. 1-5.

\begin{tabular}{|l|lll|}
\hline Journal : 11664_JEM & Dispatch : $\mathbf{1 8 - 9 - 2 0 1 5}$ & Pages : 10 \\
& Article No.: 4043 & $\square$ LE & $\square$ TYPESET \\
& $\square \mathrm{CP}$ & $\varnothing$ DISK \\
\hline
\end{tabular}


2. L. Jiang, H. Jiang, and N. Chawla, J. Electron. Mater. 41, 2089 (2012).

3. Q.K. Zhang, J. Tan, and Z.F. Zhang, J. Appl. Phys. 110, 014502 (2011).

4. S.W.R. Lee and S. Fubin, International Microsystems, Packaging, Assembly Conference Taiwan 2006, Taipei, 18-20 October, 2006, pp. 105-108.

5. J.H.L. Pang, T.H. Low, B.S. Xiong, X. Luhua, and C.C. Neo, Thin Solid Films 462-463, 370 (2004).

6. J.-W. Yoon, S.-W. Kim, and S.-B. Jung, Mater. Trans. 45, 727 (2004)

7. Y. Liu and F. Sun, J. Mater. Sci. Mater. Electron. 24 (2013).

8. C. Chen, H.-Y. Hsiao, Y.-W. Chang, F. Ouyang, and K.N. Tu, Mater. Sci. Eng. R. 73, 85 (2012).

9. T.Y. Lee, K.N. Tu, and D.R. Frear, J. Appl. Phys. 90, 4502 (2001).

10. C.-M. Chen and C.-H. Chen, J. Electron. Mater. 36, 1363 (2007).

11. Y.S. Kaganovskii, L.N. Paritskaya, V.V. Bogdanov, and A.O. Grengo, Acta Mater. 45, 3927 (1997).

12. J. Gong, C. Liu, P.P. Conway, and V.V. Silberschmidt, Scripta Mater. 60, 333 (2009).

13. C.Y. Liu and K.N. Tu, J. Mater. Res. 13, 37 (1998).

14. Y.S. Kaganovskii, L.N. Paritskaya, and V.V. Bogdanov, Powder Metall. Met. C+ 47, 652 (2008).

15. Y.C. Chan, A.C.K. So, and J.K.L. Lai, Mater. Sci. Eng. B 55, 5 (1998).

16. W. Peng, E. Monlevade, and M.E. Marques, Microelectron. Reliab. 47, 2161 (2007)

17. X. Li, F. Li, F. Guo, and Y. Shi, J. Electron. Mater. 40, 5221 (2011)

18. Z. Huijing, Q. Lin, L. Hua, Z. Ning, and M. HaiTao, 14th International Conference on Electronic Packaging Technology, Dalian, 11-14 August, 2013, pp. 372-376.

19. H. Xiao, X.Y. Li, Y.X. Zhu, J.L. Yang, J. Chen, and F. Guo, J. Mater. Sci. Mater. Electron. 24, 2527 (2013).

20. T.-T. Luu, A. Duan, K. Aasmundtveit, and N. Hoivik, J. Electron. Mater. 42, 3582 (2013).

21. H.K. Kim, H.K. Liou, and K.N. Tu, J. Mater. Res. 10, 497 (1995).
22. X. Chen, Z. Yun, F. Chonglun, and J.A. Abys, IEEE Trans. Electron. Packag. Manuf. 28 (2005).

23. M.Y. Tsai, S.C. Yang, Y.W. Wang, and C.R. Kao, J. Alloys Compd. 494, 123 (2010).

24. T. Laurila, V. Vuorinen, and J.K. Kivilahti, Mater. Sci. Eng. R. 49, 1 (2005).

25. K.N. Tu and R.D. Thompson, Acta Metall. Mater. 30, 947 (1982).

26. B.-J. Lee, N.M. Hwang, and H.M. Lee, Acta Mater. 45, 1867 (1997).

27. R.A. Gagliano, G. Ghosh, and M.E. Fine, J. Electron. Mater. 31, 1195 (2002)

28. X. Deng, G. Piotrowski, J.J. Williams, and N. Chawla, J. Electron. Mater. 32, 1403 (2003).

29. Z. Kejun, R. Stierman, C. Tz-Cheng, D. Edwards, K. Ano, and K.N. Tu, J. Appl. Phys. 97, 024508 (2005).

30. C.-C. Pan, C.-H. Yu, and K.-L. Lin, Appl. Phys. Lett. 93 (2008)

31. Y. Wu, J. Sees, C. Pouraghabagher, L.A. Foster, J. Marshall, E. Jacobs, and R. Pinizzotto, J. Electron. Mater. 22, 769 (1993).

32. H.L.J. Pang, K.H. Tan, X.Q. Shi, and Z.P. Wang, Mater. Sci. Eng. A 307, 42 (2001).

33. C. Yu, Y. Yang, J. Chen, J. Xu, J. Chen, and H. Lu, Mater. Lett. 128 (2014)

34. J.Y. Song, J. Yu, and T.Y. Lee, Scripta Mater. 51, 167 (2004).

35. K.N. Tu, C. Chen, and A. Wu, J. Mater. Sci. Mater. Electron. 18, 269 (2007).

36. M. Kawano, S. Uchiyama, Y. Egawa, N. Takahashi, Y. Kurita, K. Soejima, M. Komuro, S. Matsui, K. Shibata, J. Yamada, M. Ishino, H. Ikeda, Y. Saeki, O. Kato, H. Kikuchi, and T. Mitsuhashi, International Electron Devices Meeting 2006, San Francisco, 11-13 December, 2006, pp. 1-4.

37. Y. Seung Wook, K. Jae Hoon, N. Suthiwongsunthorn, P.C. Marimuthu, and F. Carson, IEEE International Conference on $3 D$ System Integration 2009, San Francisco, 28-30 September, 2009, pp. 1-5.

38. J. Brusse, G. Ewell, and J. Siplon, 22nd Capacitor and Resistor Technology Symposium, New Orleans, 25-29 March, 2002, pp. 67-80.

39. C.Y. Khor, M.Z. Abdullah, Z.M. Ariff, and W.C. Leong, Int Commun. Heat Mass. 39, 670 (2012).

\begin{tabular}{|l|lll|}
\hline Journal : 11664_JEM & Dispatch : 18-9-2015 & Pages : 10 \\
& Article No.: 4043 & $\square$ LE & $\square$ TYPESET \\
\hline
\end{tabular}




\section{Author Query Form}

\section{黛 Springer}

the language of science

Dear Author

During the process of typesetting your article, the following queries have arisen. Please check your typeset proof carefully against the queries listed below and mark the necessary changes either directly on the proof/online grid or in the 'Author's response' area provided below

\begin{tabular}{|l|l|l|}
\hline Query & Details Required & Author's Response \\
\hline AQ1 & Kindly check the term 'Sn99Cu1/Cu' has been changed throughout as '99Sn-1Cu/Cu'. & \\
\hline AQ2 & $\begin{array}{l}\text { As per the information provided by the publisher, Fig. 2 will be black and white in print; hence, please } \\
\text { confirm whether we can add "colour figure online" to the caption. }\end{array}$ & \\
\hline AQ3 & Kindly confirm "linear" here. & \\
\hline AQ4 & Kindly confirm this edit from "until" to "when". & \\
\hline AQ5 & Kindly confirm the stoichiometry of this equation. & \\
\hline AQ6 & Please provide page number for Refs. 7, 22, and 30. & \\
\hline AQ7 & Kindly check and confirm all the references identified correctly. & \\
\hline
\end{tabular}

